\title{
COPI Y EL TEATRO CAMP: EL ACTO DE VESTIR Y DESVESTIR COMO UNA ONTOLOGÍA DE LA IDENTIDAD EN LA OBRA TEATRAL EVA PERÓN
}

\author{
SERGIO A. MACÍAS \\ University of Denver \\ sergio.macias23@du.edu \\ ORCID: 0000-0002-1286-9016
}

\section{RESUMEN}

La obra literaria del escritor y dramaturgo franco-argentino, Raúl Damonte Botana (1939-1987) - mejor conocido por el pseudónimo de Copi-, ha despertado opiniones divididas entre la crítica literaria. Quienes se han ocupado de analizar la narrativa y el teatro de Copi argumentan que sus creaciones gestan en el lector cierta impresión de desasosiego al enfrentarse a un universo narrativo caótico y excesivo, plagado de incongruencias y personajes siniestros. Si bien es cierto que el teatro de Copi puede conceptualizarse como un esfuerzo, quizás fallido, que pretende romper con toda escuela, influencia o tradición, existen también una serie de elementos distintivos en el teatro de Copi que nos permite examinar sus obras bajo la óptica del camp -un tipo de sensibilidad asociada con la identidad queer que se caracteriza por ser frívolo, extravagante, pretencioso, incongruente, además de exhibir una fascinación por el disfraz y la ornamentación estética; pero en el fondo, representa un gesto genuino a través del cual se revela una verdad. Como estrategia, el camp nos brinda una novedosa propuesta que nos permite reconocer el valor de las inusuales creaciones de Copi, más allá de catalogar el teatro de Copi como un caso accidental o aislado. Para lograr este cometido analizo Eva Perón, la cual nos presenta una Eva Perón drag queen y desmesurada, muy al estilo camp, obsesionada con la moda y sus extravagantes vestidos. Propongo además que en la obra teatral Eva Perón, Copi nos brinda a los espectadores un tratado ontológico en el que la identidad es planteada esencialmente como un ornamento estético, vestimenta o disfraz, y el ser queda manifestad a través del acto de vestir y desvestir. En el presente estudio, primero, exploro las definiciones del camp y trazo una breve historiografía para enfocarme después en el llamado teatro camp. Posteriormente, analizo la puesta en escena de Eva Perón centrándome en las recurrentes referencias estéticas en torno a la creación de la identidad.

PALABRAS ClaVE: Copi, teatro, camp, Eva Perón, vestimenta, ontología, identidad, drag queen, travestismo, frivolidad.

\section{COPI AND CAMP THEATER: THE ACT OF DRESSING AND UNDRESSING AS THE ONTOLOGY OF THE SELF IN THE PLAY EVA PERON}

\section{ABSTRACT}

The literary works of Argentine novelist and playwright Raul Damonte Botana (1939-1987) - better known as Copi - have divided the opinion of critics. Those that have analyzed Copi's fiction and plays argue that his creations generate in readers certain feeling of uneasiness when faced with a fictional world that is chaotic, excessive, and saturated with incongruencies and evil characters. Even though Copi's theater may be conceptualized as a (failed) attempt to break free from any school of thought, influence or tradition, nonetheless there are a series of characteristics for which we may examine Copi's plays through the optics of camp - a type of sensibility 
associated with queer identity, also known for being frivolous, eccentric, and pretentious, as well as for exhibiting certain fascination with costumes and ornaments. As a reading strategy, camp enables us to recognize the value of Copi's unusual creations, beyond classifying his theater as an anomaly. In order to achieve this goal, I analyze Eva Peron, a play that presents us with a drag queen version of Eva Peron, so campy in style; she is exaggerated and obsessed with fashion and her fancy outfits. I argue that though the play Eva Peron, Copi offers an ontological treaty in which identity is essentially explained as an aesthetic artefact, an outfit or a costume, and the being is constituted by the act of dressing and undressing. In this essay, I present several camp definitions and provide a brief historical overview of this style. I proceed on to describe the characteristics for which camp theater is known. Lastly, I analyze Eva Peron by focusing on the many aesthetic references in the play that function around the idea of what it means to create an identity.

KEYWORDS: Copi, theater, camp, Eva Perón, outfits, ontology, identity, drag queen, crossdressing, frivolous.

La obra de Copi está ahí. El que quiera tomarla que la tome, y el que quiera abandonarla que la abandone. El que quiera orinar sobre su obra que la orine y el que quiera montarla sobre un altar que la monte. A Copi, desde su vida o desde su muerte, la crítica siempre le importó poco. Fue un provocador que sólo se tranquilizaba unos instantes bajo los efectos del aplauso.

(José Tcherkaski 1998: 17)

La obra literaria del escritor y dramaturgo franco-argentino, Raúl Damonte Botana (1939-1987) - mejor conocido por el pseudónimo de Copi-, ha despertado opiniones divididas entre la crítica literaria. Quienes se han ocupado de analizar la narrativa y el teatro de Copi argumentan que sus creaciones gestan en el lector cierta impresión de desasosiego al enfrentarse a un universo narrativo caótico y excesivo, plagado de incongruencias y personajes siniestros. Sobre el teatro de Copi, se ha dicho que es un caso anómalo en tanto, «carece de todo sustento teórico de la creación», no obstante, el teatro de Copi puede ser pensado, «en relación con dos aspectos fundamentales: la desmesura y la ruptura con todo lo permitido» (Tcherkaski 1998: 17). En alguna ocasión, Copi llegó a declarar que había abandonado por completo el hábito de la lectura para curarse de la «intoxicación intelectual, cultural, artística» a la que había sido sometido durante su infancia y adolescencia, para que su formación, como lector, no influyera en la creación de sus obras teatrales (Tcherkaski 1998: 30). Copi contundentemente manifestó que jamás se ocupó de la opinión de los lectores, los comentarios de los espectadores y tampoco le importó la opinión de la crítica ya que su único cometido era crear algo novedoso y asombrarse a sí mismo:

Soy el primer espectador, y el más sorprendido del espectáculo que invento, porque no utilizo un estilo lado; realmente lo que busco es la originalidad; [...] a partir de un cierto número de elementos, se trata de buscar una cosa nueva de entre todas las cosas que uno puede decir. (Tcherkaski 1998: 34)

Si bien es cierto que el teatro de Copi puede conceptualizarse como un esfuerzo, quizás fallido, que pretende romper con toda escuela, influencia o tradición, existen también una serie de elementos distintivos en el teatro de Copi que nos 
permite examinar sus obras bajo la óptica del camp - un tipo de sensibilidad asociada con la identidad queer que se caracteriza por ser frívolo, extravagante, pretencioso, incongruente, además de exhibir una fascinación por el disfraz y la ornamentación estética; pero en el fondo, representa un gesto genuino ya que, «el camp es una mentira a través de la cual se revela una verdad» (Core 1984: 81). Como estrategia, el camp nos brinda una novedosa propuesta que nos permite reconocer el valor de las inusuales creaciones de Copi, más allá de catalogar el teatro de Copi como un caso accidental o aislado. Para lograr este cometido analizo Eva Perón, la obra teatral más conocida de este ingenioso dramaturgo, la cual nos presenta una Eva Perón drag queen, desmesurada, muy al estilo camp, obsesionada con la moda y sus extravagantes vestidos. Propongo además que en la obra teatral Eva Perón, Copi nos brinda a los espectadores un tratado ontológico en el que la identidad es planteada esencialmente como un ornamento estético, vestimenta o disfraz, y el ser queda manifestad a través del acto de vestir y desvestir. En el presente estudio, primero, exploro las definiciones del camp y trazo una breve historiografía para enfocarme después en el llamado teatro camp. Posteriormente, analizo la puesta en escena de Eva Perón centrándome en las recurrentes referencias estéticas en torno a la creación de la identidad.

La palabra camp hace se debut en un diccionario de jerga victoriana, hacia finales del siglo XIX, para describir «acciones y gestos de índole exagerada implementados particularmente por individuos que exhiben una expresiva personalidad y un gusto exuberante» (Cleto 1999: 3). Sin embargo, no es sino hasta 1963, a través de la publicación de «Notes on Camp», de la autoría de Susan Sontag, que aparece la primera meditación crítica sobre el camp. En este célebre ensayo, Sontag define la esencia del camp como una insignia de identidad que se exterioriza a partir de un gusto preponderante y fascinación hacia lo artificial y lo exagerado - sobresale en la decoración de interiores y en el diseño de imagen - (Sontag 1963: 53). Más tarde, Esther Newton propone en Mother Camp que la figura más emblemática del camp son las drag queens $\mathrm{y}$, por ende, la cultura del travestismo entendida como el acto de la transformación a través de la implementación de vestimenta:

The drag queen is concerned with masculine-feminine transformation, while camp is concerned with what might be called a philosophy of transformation and incongruity. (Newton 1972: 102)

Como fenómeno cultural, el camp alcanza su auge en Estados Unidos, en la década de los sesenta, durante el movimiento queer de liberación sexual y la emancipación femenina (Amícola 2000: 13). Críticos como José Muñoz proponen el camp como una estrategia de gran valor; lo define como un proceso paradójico de des-identificación por medio de la cual, la comunidad queer se reapropia de los estereotipos y la opresión que ha sufrido y, a través del performance, los subvierte artísticamente. 
En el terreno literario, en años recientes, el camp se reconoce como un estilo de escritura que favorece la estilización del lenguaje a expensas del contenido. Se caracteriza por su deliberada predilección por lo teátrico, la parodia, lo retorcido, y la excesiva ornamentación del lenguaje a través de la adjetivación. El camp se manifiesta en todos los géneros literarios, pero en particular, este peculiar estilo sobresale en el teatro. Desde los orígenes del teatro clásico, los hombres eran quienes representaban los roles del sexo opuesto, portando máscaras que simbolizaban lo femenino, por lo que no había necesidad de recurrir a la transformación total del disfraz, como posteriormente ocurrió a partir del siglo XV. Como se mencionó anteriormente, una de las figuras emblemáticas y actividades predilectas del camp es la drag queen y el travestismo. Por este motivo, la crítica identifica un aspecto importante del llamado teatro camp. Éste emerge como un tipo de teatro queer moderno cuando, pese a que las mujeres incursionan como actrices y ocupan un lugar sobre el escenario, se opta por la transformación del travesti para representar papeles femeninos. El teatro camp se caracterizó por ser un teatro de humor negro, que también resignificaba el disfraz en un registro humorístico y en el que los temas eran típicamente abordados desde la parodia a través de una lúdica yuxtaposición de lo erótico y lo tabú. (McMahon 2011: 53). Según Herbert Brandt, el teatro camp se distingue por reutilizar el estigma en contra de homosexualidad

como un instrumento para crear un ingenioso espectáculo carnavalesco en el que las normas sociales de la burguesía y los ideales de predominantes de la cultura son invertidos y ridiculizados. (Brandt 1995: 122)

El surgimiento del teatro camp toma lugar entre 1871 y 1910, en Alemania, país que atravesaba por un rápido proceso de urbanización y, comparado con el resto de Europa, donde se disfrutaba de ciertas libertades sexuales. El teatro camp hizo de contrapeso al teatro naturalista, que intentaba representar la realidad sobre el escenario. Por el contrario, el teatro camp era una forma de expresionismo, una novedosa manifestación artística a finales del siglo XIX. El público que seguía este tipo de puesta era limitado y el espectáculo tomaba lugar bajo una carpa. Consistía en una especie de carnaval circense en el que los actores llevaban disfraces exagerados y que, como el circo, se montaba a las afueras de la ciudad. Algunos dramaturgos novatos de la época, creadores de un teatro no convencional, veían en este tipo de representación escénica la oportunidad para corroborar el efecto que producían determinada temática en el espectador, como la negatividad, los bajos instintos, lo decadente, la degeneración, la brutalidad, la lujuria, y la codicia. La mayoría de las representaciones eran cortas y contaban con pocos personajes, por lo que, se asemejaban al entremés. Estas obras se caracterizaban por:

Little conflict or suspense - little drama in the conventional sense. Like many later performances of the expressionist circus-like-stage, it consists by contrast of a series of 
images or situations. The language was highly lyrical and the set visionary, often dreamlike and sexual. Men on stage cross-dress while performing. (Brandt 1995: 33)

Durante las primeras décadas del siglo XX, Berlín se convierte en una meca para la homosexualidad masculina en tanto que brindaba, de manera sincrética, «ammenities for entertainments, such as drag shows, and an atmosphere that permitted men to cruise for sex with other men» (Brandt 1995: 45). Eventualmente el camp deja la carpa y se muda a las tabernas clandestinas. Acceder a estos lugares requería dominar un lenguaje sincrético, no verbal, que sólo los homosexuales podían descifrar, como parte de una subcultura. Estos signos estéticos, articulados a través de la adopción de un estilo, eran transmitidos entre los miembros del grupo, a la par que eran resguardados de un público heterosexual ante el temor a sufrir represalias como el encarcelamiento, la violencia física y la humillación pública. Por tanto, el espacio en el que florece el teatro camp es la taberna underground, que se pone de moda en Berlín en las primeras dos décadas del siglo XX. Estos lugares de congregación, en los que se exhibían representaciones camp acompañadas de baile y canto, disponían además de un dark-room o cuarto obscuro donde los clientes podían participar voluntariamente en orgías y otras prácticas sexuales alternativas, como el sadomasoquismo y el bondage. A estas tabernas se les denominaba «kamper». La palabra «kamper» - que además de sustantivo era un verbo- se convierte en un código para referirse a lugares en los que las puestas en escena estaban acompañadas de prácticas sexuales (Cleto 1999: 13). Una vez que el partido nazi toma el poder en los años treinta, comienzan las redadas y la depuración, no sólo judía, sino además homosexual. A partir de los años cincuenta, resurge en Francia este tipo de performances camp, pero ya no en las tabernas, sino en pequeños teatros. El teatro camp cambia de sede, pero los elementos que lo caracterizan siguen siendo los mismos.

En América Latina acontece algo realmente interesante: el teatro camp no prolifera en suelo latinoamericano, pero sí en el extranjero con temáticas y autores latinos. El teatro de Copi es un ejemplo de ello, pues la mayoría de sus obras se estrenaron en París y fueron escritas en francés, aunque sobre temas latinoamericanos. En Francia, la obra de Copi siempre fue entendida como la de un outsider. El mismo Copi se refiere irónicamente a la condición de los dramaturgos latinoamericanos en el extranjero: «No son franceses, son como yo, son los que los franceses comunistas dicen 'francés'» (Tcherkaski 1998: 36). Como dramaturgo demostró cierta innovación, siendo además un actor que fusionaba el escenario del teatro con el travestismo, una de sus grandes fascinaciones. En el teatro de Copi se distinguen una serie de elementos y temáticas, como la búsqueda de la autenticidad, el erotismo y ciertas prácticas sexuales trasgresoras y fetiches. Sus puestas en escena se caracterizaron por transgredir las fronteras de lo moral, «el discurso de las cosas siempre eran reacciones descabelladas, fragmentadas, que rompían un sistema de constructo clásico de una obra de 
teatro» (Tcherskaski 1998: 98). Copi aseveró que el teatro que escribió era reflejo de un proceso eufórico de creación, una catarsis visceral. Los guiones, por ejemplo, no estaban organizados en actos; consistían en una serie de diálogos e indicaciones sobre el disfraz de los actores en los que se describía en detalle el estado de ánimo de los personajes.

La producción teatral de Eva Perón se estrena el 2 de marzo de 1970, en el teatro de l'Epée de Bois, en París, ciudad en la que se exilia la familia de Copi ante el triunfo del partido peronista en la Argentina, en 1946. La dirección de Eva Perón estuvo a cargo de Alfredo Arias y la obra fue protagonizada por el actor Facundo Bo, aunque en un principio iba a ser Copi quien diera vida al personaje. Eva Perón fue originalmente escrita en francés, y en 2000, Jorge Montevelo hace la primera traducción al español, intentando reproducir en la obra un español argentinizado y ciertos modismos. El estreno de Eva Perón causó disturbios pues un grupo de simpatizantes peronistas se manifestaron el día del estreno y destrozaron la escenografía, lanzaron petardos, y amenazaron con incendiar el teatro y agredir al público si no se suspendía la función. A pesar del boicot, Eva Perón se estrenó y durante dos semanas, la policía parisina tuvo que resguardar el teatro. Varios medios de comunicación de la época, como el diario Le Figaro, publicaron en primera plana una reseña en la que Eva Perón fue descrita negativamente como una "pesadilla carnavalesca» y una «mascarada macabra» (Tcherkaski 1998: 8). El escándalo por el estreno de Eva Perón fue tal que a Copi se le prohibió la entrada a Argentina y no puede regresar hasta 1984. Curiosamente, Eva Perón se convirtió en un éxito de taquilla, permaneciendo veintitrés semanas en cartelera, con llenos totales.

Eva Perón es una rescritura histórica. En esta puesta en escena Copi yuxtapone lo lúdico y lo grotesco, y permitiéndose ciertas libertades creativas, nos ofrece un espectáculo camp. La trama toma lugar en la ciudad de Buenos Aires, el 26 de julio de 1952, fecha en la que muere Eva Perón a causa de un cáncer uterino. La obra hace una parodia de este trágico evento histórico de forma macabra; el cáncer que padece Eva Perón resulta ser una artimaña política orquestada por la misma Eva Perón. Con la ayuda de su círculo más cercano, Eva Perón pretende manipular emocionalmente al pueblo argentino, aprovechando la popularidad que goza, para garantizar la reelección de Juan Domingo Perón en las elecciones presidenciales que están próximas a llevarse a cabo. Eva Perón comente un asesinato el cual le permite hacer un montaje de su propia muerte. La obra culmina con la fuga de Eva Perón, quien desde el anonimato tiene planeado gozar de las diversas cuentas bancarias que abrió en el extranjero con el patrimonio que hurtó de la nación.

Eva Perón se compone de un solo acto, algo típico en las obras teatrales que escribió Copi y también del teatro camp, un tipo de teatro en corto que se representaban de corrido y se asemejaba al entremés. En escena aparecen cinco personajes, cuatro de éstos, están basados en figuras históricas reconocibles -Eva Perón; Juán Domingo Perón; Juana Ibarguren, madre de Eva Perón; y 
María Eugenia Álvarez, la enfermera a cargo de la salud de Eva Perón en su lecho de muerte-, y también aparece en escena un personaje ficticio, Ibiza, cómplice de Eva Perón. La trama se desarrolla en el interior de la residencia presidencial o la Casa Rosada. La mayoría de las acciones ocurren en la recámara de Eva Perón. La habitación, en lugar de parecer un dormitorio, se asemeja más a un camerino repleto de luces, reflectores y espejos, saturado con vestuarios, calzado, joyas, perfumes, peines, maquillaje y demás accesorios estéticos. En este espacio ocurre la caracterización de Eva Perón. La recámara establece la idea de una demarcación espacial entre lo público y lo privado, y marca la delineación de dos personajes - una Eva Perón pública y una Eva Perón privada - que sólo pueden existir dentro un plano establecido. El vestuario de Eva Perón cumple la función de disfraz posibilitando el cruce entre lo que ocurre tras bambalinas y lo que ocurre frente el ojo público. El acto de entrar y salir es análogo al acto de vestirse y desvestirse. Asimismo, la recámara de Eva Perón puede interpretarse como un armario: entrar y salir del armario implica un proceso de metamorfosis y convertirse en otra persona. El armario es el locus de la creación y configuración de la identidad, y como tal, puede ser entendido como una ontología de la identidad.

El personaje de Eva Perón que Copi nos presenta no encaja con otras Eva Perón de la ficción, creadas a partir de un tono solemne y serio - como la Santa Evita de Tomás Eloy Martínez o la Evita muñeca del cuento El simulacro, de Jorge Luis Borges, por mencionar un par de ejemplos. La Eva Perón de Copi no ensambla con los arquetipos que encarnó el personaje histórico de Eva Perón establecidos por la crítica. Los arquetipos más prevalentes son el de santa o mártir, el de prostituta, el de figura política feminista, y el de ícono internacional. A través de estos arquetipos que ha sido interpretada Eva Perón es posible «asumir una mirada crítica de los juegos de la ideología en la construcción de los saberes sobre la historia» (Grinberg 2013: 48). La creación de Eva Perón de Copi es camp en tanto representa un gesto lúdico a través del cual el dramaturgo se desentiende del contenido y de los posibles significados que pueda generar, para favorecer y enfocarse por completo en la forma y la estilización del personaje, y sin planearlo, deriva el peculiar humor camp el cual no pretende burlarse o ridiculizar a algo o alguien, sino generar diversión a través de ese algo o alguien valiéndose de yuxtaposiciones, incongruencias, exageraciones, y una serie de elementos mórbidos y siniestros que eventualmente generen asombro en el espectador (Core 1984: 81).

En esta obra, Eva Perón es representada de manera camp pues es el único personaje drag que aparece en escena. Los demás papeles fueron representados por actores cuyo cuerpo biológico correspondía al género de los personajes que interpretaron; hecho que contrasta con el personaje de Eva Perón. Eva Perón exhibe una personalidad explosiva y visceral. Su lenguaje es obsceno y vulgar. A lo largo de la obra se presenta en estado de exaltación y euforia, producto de la morfina que se inyecta a sí misma. Este hecho abre la interrogante ante el 
espectador si se trata de la verdadera personalidad de Eva Perón o es un estado inducido por la drogadicción que padece. Se suma además la declaración de Eva Perón a su madre en la que se confiesa víctima de las circunstancias: «Yo no era sí. Ustedes me hicieron así. Tú, Perón, el cáncer, todos» (Copi 2000: 20). En algunas situaciones, el personaje de Eva Perón es tan desmesurado que adquiere tintes cómicos; en otras, es siniestro y perverso, como cuando nos enteramos que «tuvo un chico y lo ahorcó con la cadena del baño» (Copi 2000: 60) o por los episodios de violencia física en contra de los demás personajes y los estados de psicosis que padece:

Ya cayó en la peor bajeza. [...] Se encerró en el placard y no quiere salir. Y antes de eso golpeó a la enfermera con una estatuilla. Se volvió loca. ¿Sabe lo que hizo? Dibujó todas las paredes de su cuarto con el lápiz de labios. Hizo dibujos obscenos. Escribió en todos lados, "A la horca con Perón". (Copi 2000: 69)

El personaje de Eva Perón contrasta radicalmente con los demás personajes, quienes se muestran sumisos y temerosos ante ella. Eva Perón es el eje central sobre el que giran el resto de los personajes y cumple una función importante en la obra: Eva Perón es quien define a los demás y otorga un valor utilitario sobre cada uno de ellos. El ejemplo más notorio es Juan Perón, personaje que mayor contrasta con la presencia y la autoridad de Eva Perón. La obra nos presenta a un Juan Perón ausente, cansado y pasivo, relata Eva Perón: «¿Sabés lo que te pasa? Tenés dos años encerrado en tu escritorio completamente muerto, con un negro que te espanta las moscas como un abanico. Sos un bueno para nada» (Copi 2000: 86). Eva Perón lo describe como un «¡Cobarde, cagón! ¡Impotente!» (Copi 2000: 74); un «viejo reseco» (Copi 2000: 64); y constantemente emascula a Juan Perón: «iAndá a esconderte bajo la cama!» (Copi 2000: 74); «Seguro te querés poner mis vestidos» (Copi 2000: 57). El personaje de Perón realmente tiene muy pocas apariciones en escena; ocasionalmente figura en escena sin articular una sola palabra. El personaje de Juan Perón existe como una ausencia y las metáforas con las que Eva se refiere a él son alusiones a seda y la suavidad de este material. Por ejemplo, las prevalentes migrañas que padece Juan Perón «son como telas de araña en el interior del cráneo» (Copi 2000: 45), mientras que la ausencia de Juan Perón se debe a que, «vive en el interior de su migraña como dentro de un capullo» (Copi 2000: 45).

Similarmente, Eva Perón se dirige a su madre despectivamente a través de insultos como: «iTurra!» (Copi 2000: 42); «Mentirosa» (Copi 2000: 43); y «vieja ridícula» (Copi 2000: 44); aunque la madre aprendió «a decir palabras chic» (Copi 2000: 39) y «a ser una dama», en el fondo «sos una vieja puta» que «hacés la calle. Sin mí no sos nada» (Copi 2000: 45). Eva Perón vive en perpetuo estado de desconfianza y paranoia. Según Eva Perón, la madre permanece a su lado solo por el interés de heredar cuando ella muera: «No te voy a dar el número de las cajas en las que tengo depositada la fortuna del Estado» (Copi 2000: 35). El abuso psicológico al que se somete Eva Perón a los personajes, particularmente a su 
madre, está constituido a partir de cambios radicales de temperamento, del desprecio a la generosidad:

Vamos, vieja, si sabés que voy a acabar por darte el número de la caja fuerte. Tené un poco de paciencia. En un mes vas a estar en Montecarlo y te la van a dar los gigolós franceses. Pintame las uñas. Dale, píntame las uñas [...] para las uñas quiero el esmalte granate. El de Revlon. ¿Queda? (Copi 2000: 43)

En numerables circunstancias, Eva Perón obsequia sus prendas como un mecanismo de manipulación de los personajes, particularmente a su madre: «Tomá. Lleválo, te lo doy. Cuídalo. Podés combinarlo con el chal dorado» (Copi 2000: 23), «ahora si parecés una dama» (Copi 2000: 45).

Eva Perón se comporta frívolamente, una actitud típica de los personajes camp. Lo único que la atañe es su imagen pública, sus vestidos, la moda; se pasa el tiempo buscando determinados vestidos que no logra localizar: «iMierda! ¿Dónde está mi vestido de mi retrato oficial? El más sencillo, con las camelias» (Copi 2000: 19). Eva Perón figura como tone deaf; lo que para Eva Perón representa sencillez, para los demás es extravagante: «¿Qué vestido presidencial, querida? Todos tus vestidos son vestidos presidenciales»(Copi 2000: 19), responde el personaje de la madre. La imagen pública o estilo que exhibe Eva Perón a través de los vestidos es interpretada por los personajes de la obra como, «otra de sus artimañas políticas» (Copi 2000: 33). Copi se vale de la fascinación de Eva Perón por la moda y aprovecha este recurso para reiterar ciertas incongruencias. Por un lado, el personaje histórico representó un símbolo de oposición a la burguesía, la oligarquía argentina, dándole voz a quienes no la tenían, los obreros y campesinos de las clases bajas o los descamisados de la nación; por otro lado, Eva Perón fue la más burguesa a través de su extravagante gusto y por los diseños de alta costura que siempre vestía.

La condición de enferma desahuciada, así como otras identidades o papeles que encarna Eva Perón en la obra, corresponde al uso de ciertas prendas. El acto de vestir y desvestirse es el mecanismo o proceso que permite a Eva Perón asumir a su antojo determinada identidad, como lo podemos constatar por las declaraciones de la enfermera: «Se levantó muy temprano para probarse sus vestidos. La seguí. La vi hacerlo. Ni siquiera está enferma. Se hace la enferma. Se viste de enferma» (Copi 2000: 23). El guardarropa de Eva Perón está organizado según un sistema en el que «cada vestido tiene un número escrito encima y a cada serie de números le corresponde un baúl diferente» (Copi 2000: 20). Eva Perón, sin embargo, organiza los vestidos por eventos o actos públicos: «el que utilicé para mi retrato presidencial» (Copi 2000: 18); «el que utilicé durante mi discurso de dominación» (Copi 2000: 20); «el más lindo de todos, el que me puse para cenar con Franco e incluso para ver al Papa» (Copi 2000: 73). O describiendo el color y la textura de los vestidos: «el rojo con camelias»; «el blanco de pedrería» (Copi 2000: 21). Sin embargo, Eva Perón es incapaz de respetar reglas o algún sistema impuesto por alguien más, «Me cago en los números» (Copi 2000: 20). La 
enfermera, en vez de ocuparse de las tareas asociadas con su profesión y oficio, se desempeña como la cosmetóloga personal de Eva Perón. Su falta de experiencia y «torpeza» impiden que satisfaga los deseos estéticos de Eva Perón: «Mire mi vestido! ¡Me lo manchó de sangre! ¡Y además le dije que me pintara las uñas de negro y usted me las pintó de rojo como una puta!» (Copi 2000: 49). En Eva Perón encontramos varias referencias de moda y alusiones a modistas, como «el diseñador Christian Dior» (Copi 2000: 62), y marcas de cosméticos, como «Revlon» (Copi 2000: 43). El universo representado dentro de la obra teatral se encuentra plagada de referencias a telas y texturas, no solo porque se remite al antiguo oficio de costurera que ejerció la madre de Eva Perón, pero también, por los negocios que son llevados a cabo, por ejemplo, «toda la plata del contrato de la lana de los portugueses» (Copi 2000: 24). Los círculos en los que se mueve Eva Perón, sobre todo el mundo de la política, son para Eva Perón pasarelas de moda:

Los embajadores trajeron a sus mujeres. Todas tienen mismo trajecito, todas. Y todos los ministros la misma corbata. Negra no, azul marino. Solamente las periodistas norteamericanas usan un trajecito rojo. Parece que también hay chicas del liceo vestidas de negro, pero yo no las vi, las ubicaron en el vestíbulo. (Copi 2000: 70)

El extravagante gusto de Eva Perón la posiciona no sólo como una experta de las últimas tendencias de moda sino, además, como alguien que critica los atuendos de las demás personas que se mueven dentro del mundo de la política.

Eva Perón nos presenta una ontología de la identidad a través del acto de vestir y desvestirse. Copi nos propone en esta obra camp que la identidad es un artificio o constructo que puede ser transferible entre los personajes. Eva Perón termina siendo un disfraz, una máscara. Esta reiteración es constatada a través de la transposición de la identidad de Eva Perón al personaje de la enfermera, quien es engañada por la misma Eva Perón para que gradualmente acceda a transformarse en su imagen:

Te gustan las joyas, ¿eh? Toma también. Y el collar. Toma, toma, no me lo agradezcas. A mí ya no me sirve para nada. ¿No tienes frío? ¿Quieres ponerte mi visón? Mira mi anillo. ¿Te gusta? Es una esmeralda, corazón, de perico. Toma, póntelo Toma, te lo regalo. Hay una peluca que combina, está guardada en la bolsa de plástico. Te la coloco. (Copi 2000: 72-79)

Durante el doble acto de vestir y desvestirse que ocurre entre el personaje de la enfermera y Eva Perón, ésta se percata de dicha transferencia, como si se tratara de un desdoblamiento de la identidad: «Déjame apoyarme sobre vos. Con este vestido es como si me apoyara sobre mí misma» (Copi 2000: 78). La obra, adquiere un tono macabro y violento cuando Eva Perón asesina a la enfermera. El elemento de perversidad queda constituido no solo a través del asesinato sino, particularmente, a través de la escena en la que Eva Perón, vestida de hombre, viola a la enfermera: 
EVITA: ¿Sos virgen?

ENFERMERA: No, señora.

EVITA: Mucho mejor. Sos muy linda ¿sabes? Tienes un cabello hermoso. No hay que teñirlo ¿eh? A la larga es malo para el pelo, ¿sabes? Déjame hacer, amor mío, permíteme. Dame. No, espera. Espera...No tengas miedo, mi amor, no tengas miedo, mi amor...quédate así...así, está. Te gusta ¿eh? Así... así....así... así. (Copi 2000: 79-82)

El acto de travestismo, consolidado a partir de la una Eva Perón drag, permite que lo que ocurre en escena genere en el espectador cierta confusión pues los límites entre el cuerpo biológico, el género y orientación sexual son diseccionados, alterados, intercambiados, transferidos y reproducidos a partir del acto de vestir y desvestir entre la enfermera y Eva Perón. Debido a la transformación de las identidades que es representada, es inevitable que el espectador no traslape sobre la escena el aura del cuerpo biológico y el género de los actores y, que aunada al intercambio de identidades que ocurren dentro de la ficción, produzca una complicada nomenclatura en la que cuerpo, género y sexualidad se difuminan se transgreden. Como tal, se abre la interrogante de que si lo que vemos en escena es un acto sexual de carácter lésbico o heterosexual. Sobre el escenario, como en su vida personal, Copi se caracterizó por comprender la identidad como un artefacto estético. En alguna ocasión declaró que:

Muchas veces he hecho de travesti, me encanta el traje de mujer, me encanta que me maquillen durante dos horas, me encanta moverme... Tengo un tipo de cosas que hace que en el teatro sea un travesti muy bueno; me encanta en el teatro vestirme de mujer, porque ser mujer es solamente eso, es vestirse de mujer. (Tcherkaski 1998: 50)

A través del personaje de drag de Eva Perón, Copi, valiéndose del disfraz y de la máscara, en su afán por recrear la feminidad, terminan subvirtiendo las categorías masculino y femenino, original-copia, develando así la misma artificialidad del género, o lo que más tarde Butler aludiría como la performatividad del género en la década de los noventa.

La obra culmina con la fuga de Eva Perón, vestida de hombre y la salida de Juán Perón al balcón, desde anuncia al pueblo el trágico deceso de Eva Perón. En el lugar de Eva Perón yace el cadáver de la enfermera, caracterizada como Eva Perón. El macabro plan resulta exitoso pues nadie percata lo que acaba de ocurrir. De esta manera Eva Perón garantiza la reelección de Juan Perón. Esta Eva Perón camp logra su principal objetivo, inmortalizarse como leyenda. No sólo a través de su legado y obra en vida - el sufragio femenino; la edificación de escuelas y hospitales; los derechos concedidos a los derechos, como «las vacaciones pagadas», «el puto recorte de la jornada laboral»-, comenta la misma Eva Perón; sino a través de lo estético, es decir, la conmemoración de unos pomposos funerales en los que se decreten «dos semanas de duelo» y por «mí extravagante forma de vestir» (Copi 2000: 56-57). Eva Perón, es una reescritura camp del personaje histórico, el cual también se dio a conocer por su fascinación de la moda y la alta costura, sino por su extravagante estilo para vestir. Copi retoma a Eva 
Perón y lo lleva a los extremos a través del camp, logrando así su tan anhelado deseo de transgredir lo establecido y crear algo novedoso y sorprendente llevándolo al límite de la desmesura. Más allá de la aparente frivolidad de Eva Perón, Copi nos obsequia una ontología de la identidad y nos plantea que la unidad esencial de la identidad y del ser, es la máscara, el disfraz y la vestimenta.

\section{BIBLIOGRAFÍA}

AmícolA, J. (2006), Camp y Posvanguardia, Buenos Aires, Paidós.

BRANDT, H. (1995), «La mariconería en el teatro: homoerotismo y homofobia», Romance Languages Annual, 95, 55-70.

BRummetT, G. (2011), The Politics of Style and the Style of Politics, New York, Lexington. Cleto, F. (1999), Camp: Queer Aesthetics and the Performing Subject, Ann Arbor, The University of Michigan Press.

COPI (2000), Eva Perón, Buenos Aires, Bourgois.

CORE, P. (1984), Camp: The Lie that Tells the Truth, London, Deliah.

DYER, R. (1977), «It's So Camp as Keeps Us Going», The Body Politic Review, 10, 80-86.

Grinberg Pla V. (2013), Eva Perón: Cuerpo, género y nación, San José, Editorial UCR.

NeWTON, E. (1972), Mother Camp: Female Impersonators in America, Englewood Cliffs, Prentice Hall.

MuÑOZ, J. E. (1999), Desidentifications, Minneapolis, University of Minnesota Press. SONTAG, S. (1956), «Notes on Camp», Partisan Review, 31, 515-30.

TCHERKASKI, J. (1998), Habla Copi: homosexualidad y creación, Buenos Aires, Galerna. 